\title{
A case of advanced hepatocellular carcinoma cured with antiviral therapy and sorafenib
}

\author{
Steven Krawitz ${ }^{1}$, Flavius Guglielmo ${ }^{2}$ and Hie-Won Hann ${ }^{1 *}$ \\ ${ }^{1}$ Division of Gastroenterology and Hepatology, Department of Medicine, Thomas Jefferson University Hospital, Philadelphia, USA \\ ${ }^{2}$ Department of Radiology, Thomas Jefferson University Hospital, Philadelphia, USA
}

\begin{abstract}
Hepatocellular carcinoma (HCC) continues to be a devastating complication of chronic hepatitis B virus (HBV) infection. Local ablative therapies for small HCC are successful, but treatment of advanced HCC is severely lacking. Sorafenib is the only current therapy for advanced HCC. However its benefit is limited to a short gain in survival. Recently, studies have shown survival benefit of antiviral therapy for HBV associated HCC. We present a case where a large advanced HCC achieved a cure following combined therapy with sorafenib and anti-HBV drugs. It appears that in addition to sorafenib, continuous suppression/elimination of the virus with anti-HBV therapy prevented new/recurrent HCC while the remaining tumor was locally ablated.
\end{abstract}

Core tip: In addition to sorafenib to control the existing tumor, antiviral drugs can prevent the development of new or recurrent cancer by suppressing the viral (the hepatocarcinogen) replication. Another point is the patient's attitude and compliance. This patient was determined to receive maximum sorafenib treatment and tolerated the severe side effects and was able to achieve this favorable result.

\section{Introduction}

Hepatocellular carcinoma (HCC) is the third leading cause of cancer death globally $[1,2]$. Individuals with chronic HBV from endemic areas are at high risk of developing cirrhosis and independently of developing HCC over their lifetimes. Current therapies for HCC are mostly limited to local ablative therapies ideally suited for smaller tumor sizes. More advanced HCC is difficult to treat locally and relies mostly on palliative chemotherapy (sorafenib). Survival for patients with advanced HCC is still very poor and further research is desperately needed.

\section{Case presentation}

In April 2009, a 57-year-old Asian male with chronic hepatitis B presented with severe abdominal pain and liver mass. Pertinent past history showed that at age 23 , he received blood transfusion during a right upper lobectomy for pulmonary tuberculosis. Family history was unrevealing and was negative for hepatitis $\mathrm{B}$. He was noted to be HBsAg positive at the age 30 on a routine examination. He remained well and did not receive antiviral therapy until July 2007 when he was evaluated by his family physician. Laboratories showed a positive HBeAg with a $\mathrm{HBV}$ viral load of $4.3 \times 10^{4} \mathrm{IU} / \mathrm{ml}$. ALT was $42 \mathrm{U} / \mathrm{L}$ with a platelet count

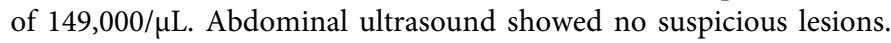
His physician initiated treatment with lamivudine (LAM) $150 \mathrm{mg}$ daily in July 2007 followed by tenofovir (TDF) $300 \mathrm{mg}$ daily two years later.

During the visit in April, 2009, his abdominal CT scan showed a $12.9 \times 10.9 \mathrm{~cm}$ mass in the right lobe of the liver with right portal vein tumor thrombus and tumor thrombus extending into in the inferior vena cava. There was also a right adrenal gland metastasis (Figure 1a and $1 \mathrm{~b})$.
Alpha-fetoprotein (AFP) at this time was found to be $21,467 \mathrm{ng} /$ $\mathrm{ml}$. HBV viral load was measured at $85 \mathrm{IU} / \mathrm{ml}$ despite continued dual therapy of LAM and TDF, and his compliance was admitted to be poor. Full anticoagulation was initiated with warfarin. Antiviral therapy was continued with both LAM and TDF and sorafenib was started at a dosage of $400 \mathrm{mg}$ twice daily in June 2009. HBV DNA became undetectable in October 2009.

The patient was determined to receive the maximum treatment available. He took sorafenib $800 \mathrm{mg}$ daily despite severe side effects of rash and hand foot mouth syndrome. His hands and feet (soles) were erythematous and severely exfoliated which were managed with

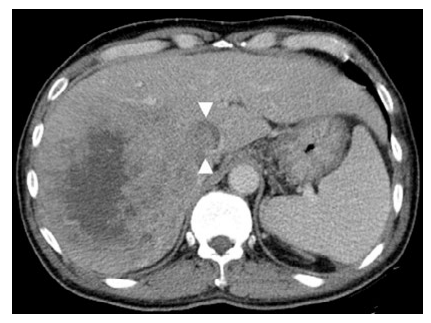

$1 \mathbf{a}$

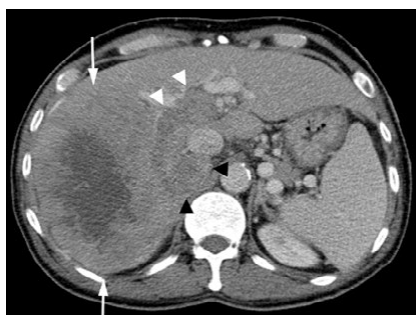

$1 \mathbf{b}$
Figure 1. Contrast enhanced CT scan.

(a) Showing a large enhancing mass (arrows) with central necrosis in the right hepatic lobe. There is enhancing tumor thrombus distending the main, right and left portal vein (white arrowheads) and a metastasis in the right adrenal gland (black arrowheads). (b) There is enhancing tumor thrombus distending the inferior vena cava (arrowheads).

Correspondence to: Hie-Won Hann, Liver Disease Prevention Center, Division of Gastroenterology and Hepatology, Thomas Jefferson University Hospital, 1025 Walnut Street, Philadelphia, PA 19107, USA, Tel: +1-215-955-5806, Fax: +1-215-955-0770, E-mail: hie-won.hann@jefferson.edu

Key words: hepatocellular carcinoma (HCC), sorafenib, antiviral therapy, tumor ablation, Hepatitis $B(H B V)$

Received: December 22, 2015; Accepted: January 11, 2016; Published: January 15,2016 
skin lotion. By July 2009, in a month on sorafenib and continued dual antiviral therapy, the AFP decreased to $736 \mathrm{ng} / \mathrm{ml}$ and by September 2009 had fallen further to $138 \mathrm{ng} / \mathrm{ml}$. MRI obtained at this time showed the tumor had decreased in size to $7 \times 7.4 \mathrm{~cm}$ (not shown). The patient continued his antiviral and sorafenib therapy $(600 \mathrm{mg}$ daily since October, 2009). Repeat imaging with gadolinium enhanced MRI in December 23, 2009 showed further shrinking of the tumor to $5.3 \times$ $4.8 \mathrm{~cm}$ as shown in Figure 2a and $2 \mathrm{~b}$.

The Tumor mass was predominantly necrotic except for an enhancing $1 \mathrm{~cm}$ recurrence at the anterolateral aspect. AFP was 137 ng/ml. In February 2010, he underwent successful transarterial chemoembolization (TACE), after which his AFP decreased further to $2 \mathrm{ng} / \mathrm{ml}$ in May 2010. Throughout this entire period, HBV DNA has remained undetectable since October 2009. Gadolinium enhanced MRI in June 2011, 18 month following TACE showed the treated tumor mass decreased in size $(4.5 \times 4.4 \mathrm{~cm})$, completely necrotic without residual viable tumor as shown below in Figure 3. The IVC tumor thrombus and portal vein tumor thrombus continued to improve in appearance. The right adrenal metastasis became completely necrotic and nonviable.

MRI in April 2014 showed fully treated tumor with only an ablation cavity without viable tumor as shown in Figure 4. The portal vein has recanalized with improved cavernous transformation. The IVC thrombus is improved. The right adrenal gland appeared normal.

To date in 2015, the patient continues on the same medication regimen and remains with AFP less than $2 \mathrm{ng} / \mathrm{ml}$ and undetectable $\mathrm{HBV}$ viral load without signs of HCC recurrence as summarized in Table 1.
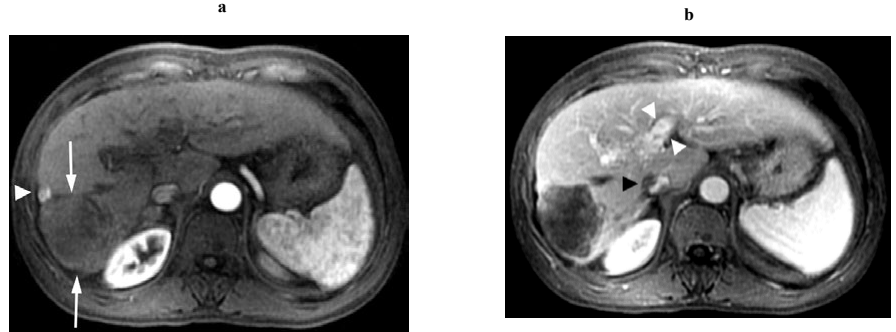

Figure 2. Gadolinium enhanced MRI performed 7 months later.

(a) The mass is predominantly necrotic and significantly decreased in size (arrows). However, there is an enhancing $1 \mathrm{~cm}$ nodule anterolaterally, representingresidual viable tumor (arrowhead). (b) The portal vein tumor thrombus is significantly improved with partial recanalization (arrowheads) and the IVC tumor thrombus is significantly decreased in size (black arrowhead).

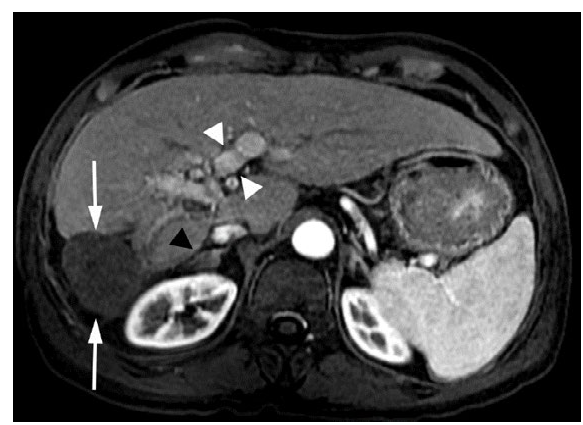

Figure 3. Gadolinium enhanced MRI performed 18 months later.

The mass is necrotic without residual viable tumor and is decreased in size (arrows). There is continued portal vein recanalization (white arrowheads). The right adrenal metastasis is significantly decreased in size (black arrowhead). a

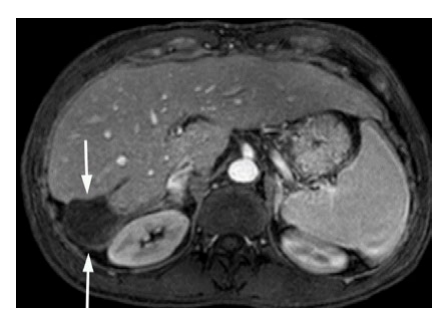

b

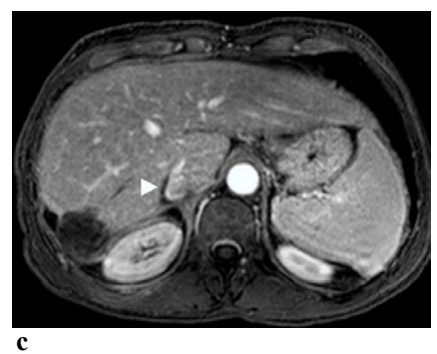

Figure 4. Gadolinium enhanced MRI performed 3 years later.

(a) The treated lesion is decreased in size without viable tumor. (b) The portal vein has recanalized (arrowheads). (c) The IVC tumor thrombus is resolved with minimal residual scarring (arrowhead). The right adrenal gland appeared normal (not shown).

\section{Discussion}

Sorafenib is a small molecule that inhibits multiple tyrosine and serine/threonine kinases involved in cell proliferation and angiogenesis. Sorafenib has both anti-proliferative and anti-angiogenic anti-tumor properties through its inhibitory modulation of the protein kinase RAF [3,4]. Many steps of carcinogenesis rely on activated receptor tyrosine kinases (RTK) and their cascades leading to activation of several potential pro-oncogenic factors including epidermal growth factor, platelet derived growth factor, and vascular-endothelial growth factors. RAF kinases are downstream effector molecules of RKT's that encourage cell division which can lead to tumor progression/formation.

The phase 3 trial by Llovet et al. [5] was the first of its kind to demonstrate the efficacy of sorafenib for HCC. In this trial the median overall survival was 10.7 months in the sorafenib group (dosed 400 mg twice daily) versus 7.9 months in the placebo group $(\mathrm{p}<0.001)$. Overall survival benefit was likely due to increased time to progression. However there was no significant difference in time to symptomatic progression. A second study was with the patient population from the Asia-Pacific region by Cheng et al. [6]. The study confirmed the efficacy of sorafenib. In this trial, patients treated with sorafenib had a median overall survival of 6.5 months compared to 4.2 months in the placebo group ( $\mathrm{p}<0.014)$. Again, the study mainly demonstrated a significant benefit in time to progression, which has since been confirmed by Bruix et al. [7].

The above presented case demonstrates a startling regression and cure of an advanced HCC in the setting of sorafenib treatment. This is beyond what would be expected from prior studies. One difference in this case is the concomitant antiviral therapy for HBV. With continuous suppression/elimination of the virus (the hepatocarcinogen) with antiviral administration, no new tumor developed while the remaining tumor was locally ablated. 
Table 1. Response of HCC to Sorafenib and antiviral treatment.

\begin{tabular}{|c|c|c|c|c|c|c|c|c|}
\hline Date & Treatment & $\begin{array}{c}\text { Anti-cancer } \\
\text { treatment }\end{array}$ & $\begin{array}{l}\text { Local tumor } \\
\text { ablation }\end{array}$ & $\begin{array}{l}\text { HBV DNA } \\
\text { levels }\end{array}$ & $\underset{(\mathbf{n g} / \mathbf{m l})}{\mathbf{A F P}}$ & $\begin{array}{c}\text { MRI } \\
\text { Tumor size (cm) }\end{array}$ & Description & Figure \\
\hline $5 / 2009$ & LAM+TDF & ND & ND & $85 \mathrm{IU} / \mathrm{ml}$ & 21,467 & $\begin{array}{c}12.9 \times 10.9 \\
\text { (viable Tumor) }\end{array}$ & $\begin{array}{c}\text { enhancing with central } \\
\text { necrosis }\end{array}$ & 1 \\
\hline $7 / 2009$ & LAM+TDF & Sorafenib & ND & ND & 736 & ND & ND & \\
\hline 9/2009 & LAM+TDF & Sorafenib & ND & UD & 138 & $7 \times 7.4$ & ND & \\
\hline $12 / 2009$ & LAM+TDF & Sorafenib & & UD & 137 & $\begin{array}{c}5.3 \times 4.8 \\
\text { (treated scar) }\end{array}$ & necrotic, no viable tumor & 2 \\
\hline $2 / 2010$ & LAM+TDF & Sorafenib & TACE & UD & 2.0 & ND & ND & \\
\hline $6 / 2011$ & LAM+TDF & Sorafenib & ND & UD & 1.6 & $\begin{array}{c}4.5 \times 4.4 \\
\text { (treated scar) }\end{array}$ & necrotic, no viable tumor & 3 \\
\hline $4 / 2014$ & $\mathrm{LAM}+\mathrm{TDF}$ & Sorafenib & ND & UD & 1.4 & $\begin{array}{c}3.8 \times 3.5 \\
\text { (treated scar) }\end{array}$ & necrotic, no viable tumor & 4 \\
\hline
\end{tabular}

ND: not done, UD: undetectable, LAM: Lamivudine, TDF: Tenofovir Disoproxil Fumarate

Studies have shown survival benefit of antiviral therapy for chronic HBV in the setting of HCC. A study by Hann et al. demonstrated an improvement in survival from 16 months to 80 months $(\mathrm{p}=0.001)$ in patients with chronic HBV and a newly diagnosed HCC $\leq 7 \mathrm{~cm}$ when treated with antivirals along with tumor ablation compared to those not given antivirals [8]. Improved survival is likely due mainly to prevention of recurrent HCC, although preserved liver function also likely contributes [9]. Indeed, high viral load is considered a risk factor for development of HCC and its recurrence. Recently Lim et al. in their study of sorafenib treatment in HCC patients observed that high HBV DNA was associated with poor response to sorafenib [10]. Incidentally, our case had low baseline HBV DNA of $85 \mathrm{IU} / \mathrm{ml}$ (494 copies/ml) at the time of HCC diagnosis as the result of prior antiviral therapy. Also, ground glass hepatocytes (GGHs) that harbor pre-S deletion mutants are known to be preneoplastic lesions and associated with recurrence [11-14]. Even though we did not obtain biopsy, it is possible that this patient did not have the GGHs with the mutation. We believe our case is perhaps the first advanced HCC that receded successfully to Sorafenib and antiviral treatment combined with one TACE procedure.

Hepatocellular carcinoma continues to be a devastating complication of chronic hepatitis B. Although local ablative therapies for small HCC are becoming more successful, treatment of advanced HCC is severely lacking. Sorafenib is currently the only approved targeted therapy for advanced HCC but its benefit is limited to a short gain in survival.

We present a case where a large advanced HCC had a dramatic response to sorafenib leading to cure. Further research into tumor biology and biochemistry might provide clues as to why some tumors might respond better than others, and coupled with continued treatment development might make more significant breakthroughs for the treatment of HCC. Intratumoral heterogeneity of HCC has already been described, particularly in large HCCs and is implicated with tumor behavior such as an early tumor recurrence in certain subgroup [15,16]. Improved targeted therapies, combined with effective viral suppression with antiviral therapy, might significantly affect the prognosis of patients with HCC associated with chronic hepatitis B.

\section{Institutional review board statement}

IRB approval not needed for one case report at Thomas Jefferson University.

\section{Conflict of interest statement}

Hann receives clinical research grants from Gilead Sciences and Bristol-MyersSquibb, Krawitz- none, Guglielmo-none.

\section{References}

1. (2011) Surveillance Research Program, National Cancer Institute Fast Stats: an interactive tool for access to SEER cancer statistics.

2. Ferlay J, Shin HR, Bray F, Forman D, Mathers C, et al. (2010) Estimates of worldwide burden of cancer in 2008: GLOBOCAN 2008. Int J Cancer 127: 2893-2917. [Crossref]

3. Forner A, Llovet JM, Bruix J (2012) Hepatocellular carcinoma. Lancet379: 1245-1255. [Crossref]

4. Wilhelm Sm, Carter C, Tang L,Wilkie D, McNabola A, et al. (2004) BAY 43-9006 exhibits broad spectrum oral antitumor activity and targets the RAF/MEK/ERK pathway and repecptor tyrosine kinases involved in tumor progression and angiogenesis. Cancer Res64:7099-7109.[Crossref]

5. Llovet JM, Ricci S, Mazzaferro V, Hilgard P, Gane E, et al. (2008) Sorafenib in advanced hepatocellular carcinoma. $N$ Engl J Med359: 378-390.[Crossref]

6. Cheng AL, Kang YK, Chen Z, Tsao CJ, Qin S, et al. (2009) Efficacy and safety of sorafenib in patients in the Asia-Pacific region with advanced hepatocellular carcinoma: a phase III randomised, double-blind, placebo-controlled trial. Lancet Oncol10: 25-34. [Crossref]

7. Bruix J, Raoul JL, Sherman M, Mazzaferro V, Bolondi L, et al. (2012) Efficacy and safety of sorafenib in patients with advanced hepatocellular carcinoma: subanalyses of a phase III trial. J Hepatol57: 821-829.[Crossref]

8. Hann HW, Coben R, Brown D, Needleman L, Rosato E, et al. (2014) A long-term study of the effects of antiviral therapy on survival of patients with HBV-associated hepatocellular carcinoma (HCC) following local tumor ablation. Cancer Med3:390396.[Crossref]

9. Cheng AL, Kang YK, Chen Z, Tsao CJ, Qin S et al. (2009)Efficacy and safety of Sorafenib in patients in the Asia-Pacific region with advanced hepatocelluar carcinoma: a phase III randomized double-blind, placebo-controlled trial. Lancet Oncol10:25-34. [Crossref]

10. Lim S, Han J, Kim GM, Han KH, Choi HJ (2015) Hepatitis B viral load predicts survival in hepatocellular carcinoma patients treated with sorafenib. J GastroenterolHepatol30: 1024-1031.[Crossref]

11. Wang HC, Huang W, Lai MD, Su IJ (2006) Hepatitis B virus pre-S mutants, endoplasmic reticulum stress and hepatocarcinogenesis. Cancer Sci97: 683-688.[Crossref]

12. Yang JC, Teng CF, Wu HC, Tsai HW, Chuang HC, et al. (2009) Enhanced expression of vascular endothelial growth factor-A in ground glass hepatocytes and its implication in hepatitis B virus hepatocarcinogenesis. Hepatology49: 1962-1971.[Crossref]

13. Tsai HW, Lin YJ, Lin PW, Wu HC, Hsu KH, et al. (2011) A clustered groundglass hepatocyte pattern represents a new prognostic marker for the recurrence of hepatocellular carcinoma after surgery. Cancer 117: 2951-2960.[Crossref]

14. Mathai AM, Alexander J, Kuo FY, Torbenson M, Swanson PE, et al. (2013) Type II ground-glass hepatocytes as a marker of hepatocellular carcinoma in chronic hepatitis B. Hum Pathol44: 1665-1671.[Crossref] 
15. Friemel J, Rechsteiner M, Frick L, Böhm F, Struckmann K, et al. (2015) Intratumor heterogeneity in hepatocellular carcinoma. Clin Cancer Res21: 1951-1961.[Crossref]
16. Yuan RH, Jeng YM, Hu RH, Lai PL, Lee PH, et al. (2011) Role of p53 and $\hat{\mathrm{I}}^{2}$-catenin mutations in conjunction with CK19 expression on early tumor recurrence and prognosis of hepatocellular carcinoma. J GastrointestSurg15: 321-329.[Crossref]

Copyright: (C) 2016 Krawitz S. This is an open-access article distributed under the terms of the Creative Commons Attribution License, which permits unrestricted use, distribution, and reproduction in any medium, provided the original author and source are credited. 